\title{
TEMPERATURE CHANGES IN BONE USING AN AIR SCALER EX VIVO
}

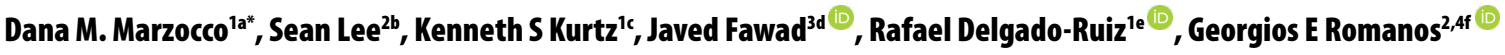 \\ 'Department of Prosthodontics and Digital Technology, Stony Brook University, Stony Brook, New York, USA \\ ${ }^{2}$ Department of Periodontology, School of Dental Medicine, Stony Brook University, Stony Brook, New York, USA \\ ${ }^{3}$ Department of Orthodontics, Eastman Institute for Oral Health, University of Rochester, NY, USA \\ ${ }^{4}$ Department of Oral Surgery and Implant Dentistry, School of Dental Medicine, Johann Wolfgang Goethe University, Frankfurt, Germany
}

aDMD, Clinical Assistant Professor; e-mail: danamarzocco@gmail.com; ORCIDiD:

bDMD; e-mail: sean.t.lee11@gmail.com; ORCIDiD:

'DDS, FACP, Clinical Professor, Director; e-mail: kenneth.kurtz@stonybrookmedicine.edu; ORCIDiD:

dBDS, PhD; e-mail: fawjav@gmail.com; ORCIDiD: https://orcid.org/0000-0002-9253-1989

eDDS, MSc, PhD Associate Professor; e-mail: rafael.delgado-ruiz@stonybrookmedicine.edu; 0RCIDiD: https://orcid.org/0000-0003-1721-0509

'DDS, PhD, DMD, Professor, Director; e-mail: georgios.romanos@stonybrookmedicine.edu; ORCIDiD: https://orcid.org/0000-0002-5952-4752

Introduction Frictional forces induced by osteotomy devices may induce an unwanted temperature increase in bone. This experimental study aimed to evaluate temperature changes produced in dense bone by three different osteotomies produced by an air scaler device.

Methodology Under the same parameters, forty-five linear osteotomies were prepared on the cortical layer of fresh porcine ribs resembling dense bone with three different air scaler insert tips: sagittal saw (Tip A), diamond ball (Tip B) and square chisel (Tip C). The length of the osteotomies was standardized to $10 \mathrm{~mm}$ in length. The depths of cuts ranged from $0.5 \mathrm{~mm}$ to $2.0 \mathrm{~mm}$. The future osteotomy areas were marked with a graphite pen, and thermocouple microprobes were placed $1 \mathrm{~mm}$ lateral at both sides of the marks. The maximum temperature, differential temperature, and time for cut completion were recorded. Analysis of Variance and Kruskal Wallis test were used for the group comparisons.

Results Tip A induced the highest of the maximum temperature recordings (Tip A: $48.0^{\circ} \mathrm{C}$ ). Tip B and C produced comparable maximum temperatures (Tip B: $43.6^{\circ} \mathrm{C}$ and Tip $\mathrm{C}: 44.0^{\circ} \mathrm{C}$ ). Total mean temperature change increased more for Tip B (4.13) and less in Tip C (0.2). Timing of cuts ranged from 30 seconds to 5 minutes $(2.30 \pm 1.76 \mathrm{~min})$. Overall average temperature change was less than $100{ }^{\circ} \mathrm{C}$ within one minute. Conclusion Osseous site preparation can be achieved with the Air scaler and different air scaler inserts without inducing significant critical thermal changes in bone.

\section{KEYWORDS}

Air Saler; Heat Generation; Osteotomy; Sonic Device; Temperature Change.

\section{INTRODUCTION}

Bone osteotomy is a frequent procedure in oral and orthopedic surgery [1]. In addition to the conventional rotary and manual methods, there are a number of instruments and techniques that can be utilized for an osteotomy. These include laser, water jet, and ultrasonic instruments [2]. The air scaler device may be useful for procedures including implant bed preparation, linear osteotomies, sinus augmentation, bone harvesting and bone splitting. This sonic device operates using compressed air at a lower frequency $(6,000 \mathrm{~Hz})$ than other respective

(c) (1) \& $(9)$ OPEN ACCESS This is an Open Access article under the CC BY-NC 4.0 license. Peer-Reviewed Article

Citation: Marzocco DM, Lee S, Kurtz KS, Calvo-Guirado JL, Fawad J, Romanos GE. Temperature changes in bone using an air scaler Ex Vivo, Stoma Edu J. 2020;7(4):252-258.

Received: October 32, 2020; Revised: November 02, 2020; Accepted: November 13, 2020; Published: November 16, 2020

*Corresponding author: Dana M. Marzocco; School of Dental Medicine, Stony Brook University, 1100 Westchester Hall, Stony Brook, NY $11794-8712$

Tel/Fax: (631) 632-3161; e-mail: danamarzocco@gmail.com

Copyright: $\odot 2020$ the Editorial Council for the Stomatology Edu Journal. 


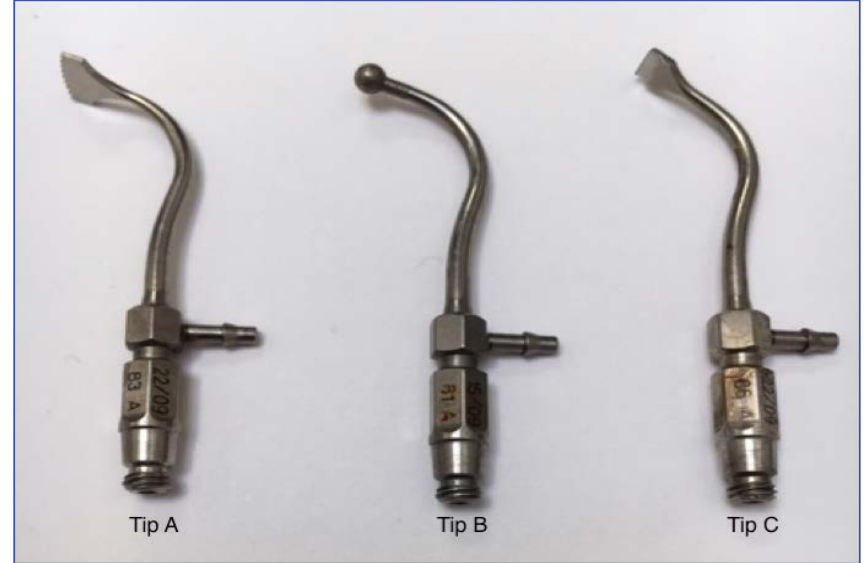

Figure 1. Air scaler tips for the ex vivo study; left to right Tip A (sagittal saw), Tip B (diamond ball), Tip C (square chisel).

devices. The use of an air scaler with internal irrigation is thought to protect the surrounding nerves and soft tissues during the preparation of osseous structures [3]. There have been previous studies, which indicated both sonic and ultrasonic devices resulted in almost no signs of damage to the bone [4]. The thermal changes induced by osteotomy devices can irreversibly affect the bone [5]. It has been demonstrated that an increase in 10 or more degrees (over a normal body temperature of $37^{\circ} \mathrm{C}$ ) for one minute could induce unwanted effects in osseous structures such as osteocyte death, empty lacunae, and reduced vascularization (also called bone osteonecrosis) [6,7].

An additional study [8], also indicated that the bone regeneration was reduced when the temperature was increased. It has been shown that consistent heating over $50^{\circ} \mathrm{C}$ for one min has induced in vitro bone tissue necrosis [9]. As a consequence of the frictional forces exerted by cutting instruments during the osteotomy, the bone temperature is increased. The mechanism for thermal osteonecrosis is multifactorial; the local increment of temperature can induce dehydration of the bone tissues, the osteocytes will suffer rupture of the cellular membrane (apoptosis), and the bone vascularization will be reduced, resulting in bone ischemia. Besides, pre-osteoclastogenic gene expression is increased by initiating bone resorption [10].

The thermal effects induced by the air scaler during osteotomies are unknown; the potential effects of different scaler tips are not clear. The purpose of this study was to assess ex vivo the temperature changes induced by an Air scaler instrument in bone preparation.

\section{METHODOLOGY}

An air scaler (Sonicflex quick 2008/L; KaVo, Biberach an der Riss, Germany) was used in this investigation.

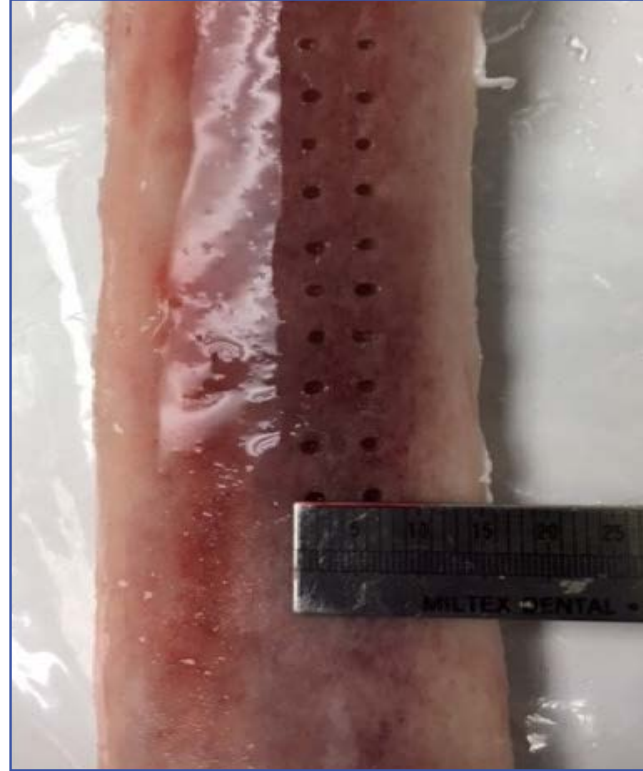

Figure 2. Osteotomies in the bovine rib bone.

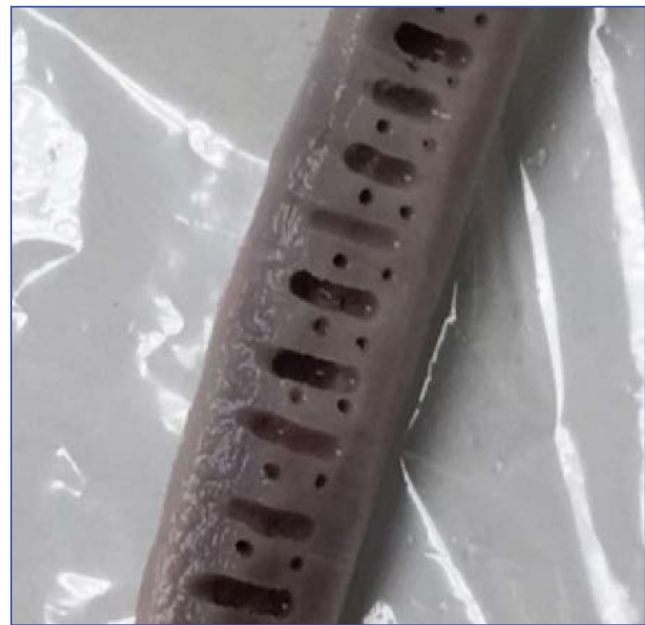

Figure 3. Location of the thermocouples and osteotomies prepared by the air scaler.

The air scaler was set to output level $3(6,000$ $\mathrm{Hz}$, amplitude $240 \mu \mathrm{m}, 71 \mathrm{~dB}$ ). The air scaler was operated using internal irrigation with $50 \%$ of water flow. Three surgical tips were selected for this study (Fig. 1):

- Tip A - Sonicflex bone tip, sagittal saw (\#83),

- Tip B - Sonicflex bone tip, diamond coated ball (\#81) and the

- Tip C - Sonicflex bone tip, square chisel (\#80).

Tip A (sagittal saw) and Tip C (square chisel) had polished, steel cutting surfaces. Tip B (diamond ball), had a rough diamond cutting surface (Fig. 1). For this ex vivo study, cuts were made in fresh dense bovine rib. The rib was denuded from soft tissues and the surface was cleaned with water. The bovine rib was placed on a flat surface for standardization of the osteotomies. Room temperature was used as the initial surface temperature.

A template was prepared and transferred to the rib for each of the tips. The template indicated twenty 
ITable 1. Temperature changes in relation to the used tip of the air scaler.

\begin{tabular}{|l|l|l|l|l|}
\hline Tip & $\begin{array}{l}\text { Mean Temp } \\
\text { Change }\left({ }^{\circ} \mathrm{C}\right)\end{array}$ & $\begin{array}{l}\text { Total Mean } \\
\text { Temp Change }\left({ }^{\circ} \mathrm{C}\right)\end{array}$ & $\begin{array}{l}\text { Standard } \\
\text { Deviation }\left({ }^{\circ} \mathrm{C}\right)\end{array}$ & $\begin{array}{l}\text { Average Standard } \\
\text { Deviation }\left({ }^{\circ} \mathrm{C}\right)\end{array}$ \\
\hline A - Saw & $\begin{array}{l}\text { A1 } 1.38 \\
\text { A2 }-1.41\end{array}$ & -0.01 & $\begin{array}{l}\text { A1 } 6.02 \\
\text { A2 5.8 }\end{array}$ & 5.83 \\
\hline B - Ball & $\begin{array}{l}\text { B1 } 0.2 \\
\text { B2 } 5.58\end{array}$ & 4.13 & $\begin{array}{l}\text { B1 4.08 } \\
\text { B2 4.04 }\end{array}$ & 4.26 \\
\hline C - Chisel & $\begin{array}{l}\text { C1 } 0.2 \\
\text { C2 } 0.2\end{array}$ & 0.2 & $\begin{array}{l}\text { C1 5.8 } \\
\text { C2 4.4 }\end{array}$ & 5.14 \\
\hline
\end{tabular}

ITable 2. Required times for osteotomy procedures using different inserts.

\begin{tabular}{|l|l|l|l|l|l|l|l|l|l|}
\hline Variable & Count & Mean & Minimum & $\begin{array}{l}\text { Lower } \\
\text { Whisker }\end{array}$ & Q1 & Median & Q3 & $\begin{array}{l}\text { Upper } \\
\text { Whisker }\end{array}$ & Max \\
\hline Tip A & 15 & $\begin{array}{l}3.4326 \\
7\end{array}$ & 1 & 1.72685 & 2.01 & 3.3 & 5 & 5.13848 & 5.3 \\
\hline Tip B & 15 & $\begin{array}{l}2.9566 \\
7\end{array}$ & 0.27 & 1.19994 & 1.165 & 3.05 & 5.03 & 4.71339 & 5.05 \\
\hline Tip C & 15 & 1 & 1 & 1 & 1 & 1 & 1 & 1 & 1 \\
\hline
\end{tabular}

Table 3. Maximum temperature changes for different inserts.

\begin{tabular}{|l|l|l|l|l|l|l|l|l|l|}
\hline Variable & Count & Mean & Minimum & $\begin{array}{l}\text { Lower } \\
\text { Whisker }\end{array}$ & Q1 & $\begin{array}{l}\text { Media } \\
\mathrm{n}\end{array}$ & Q3 & $\begin{array}{l}\text { Upper } \\
\text { Whisker }\end{array}$ & Max \\
\hline Tip A & 30 & $\begin{array}{l}26.073 \\
3\end{array}$ & 8 & 19.12287 & 22.475 & 26.9 & 29.75 & 33.0238 & 48 \\
\hline Tip B & 30 & 30.01 & 23.8 & 25.5071 & 27.125 & 29.05 & 31.65 & 34.5129 & 43.6 \\
\hline Tip C & 30 & 31.1 & 25 & 25.59546 & 28 & 30 & 32 & 36.6045 & 44 \\
\hline
\end{tabular}

individual cuts approximately $10 \mathrm{~mm}$ in length (Fig. 2). The width of each cut was indicated by the individual surgical tip.

Agraphitepencil wasutilized to mark the approximate position of the proposed cuts and placement of the thermocouples. Two thermocouples (Model no. IT-23 Thermocouple microprobe, diameter .003" insulated with extruded TFE Teflon, Physitemp instruments, Clifton, NJ, USA) were utilized to assess the thermal changes. One was placed at the coronal end of the proposed cut, the second at mid-length aspect. Thermocouples sites (coronal and mid-length were placed approximately $1 \mathrm{~mm}$ lateral to each proposed cut) (Fig. 3).

The sites for each thermocouple were prepared prior to performing the proposed cuts. Each thermocouple was secured in cortical and cancellous bone. All tips were new and unused. Each tip (A, B, C), was used to make 15 cuts each in the bovine rib; 45 osteotomies were performed in total.

For each subsequent osteotomy, the bovine rib was allowed to return to the room temperature of $21^{\circ} \mathrm{C}$. Thermocouples were relocated to the next osteotomy site and were monitored for their stabilization at room temperature.

Once the room temperature was noted, the next cut could be performed and recorded. Timing was recorded in seconds and minutes with the beginning of the cut and ended when the operator completed the cut. The length of cuts was predetermined to $10 \mathrm{~mm}$ using the template as described previously. All cuts were performed by the same operator. Thermocouples were connected to an electronic digital thermometer system (ADInstruments, Inc., Colorado Springs, CO, USA) that allowed the continuous reading of the temperatures. Each site (coronal and mid-length) had an individual output. The output from each thermocouple was recorded individually. A software program (Lab Chart, ADInstruments, Inc.) was used to record temperature readings (in Celcius), from each thermocouple.

\subsection{Statistical Analysis}

The average temperature change was calculated for the mid-length and laterally positioned 


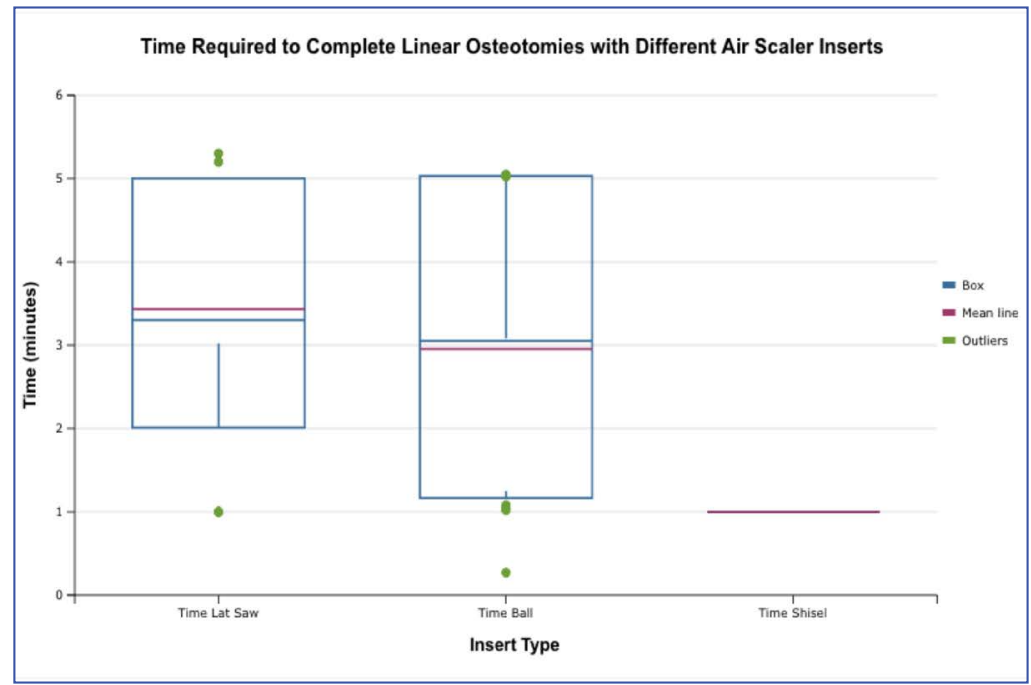

Figure 4. Box plot showing the times required for osteotomies using the different a Air scaler inserts.

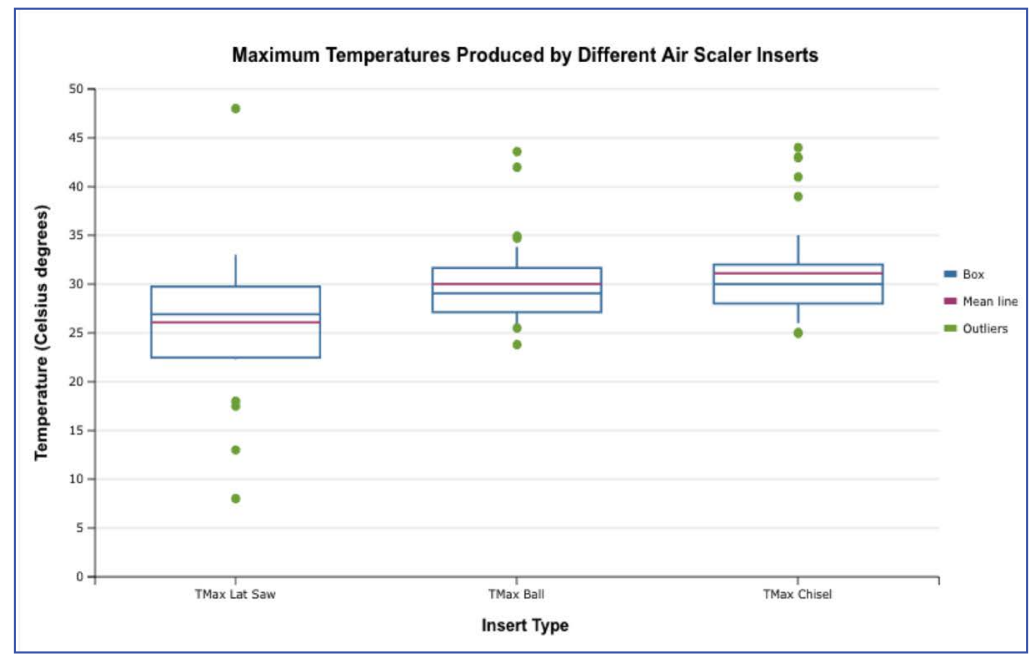

Figure 5. Box plot showing the maximum temperature increase for osteotomies performed ex vivo using an air scaler with different inserts.

thermocouples (Table 1). An average temperature change was determined for each tip $(A, B, C)$. The standard deviation was calculated for the mid-length and lateral thermocouples. An average standard deviation was determined for each tip $(A, B, C)$, as well as time.

Descriptive statistics, mean and standard deviations, and lower and maximum quartiles were used to present the data. ANOVA analysis was used for the comparison of maximum temperatures between groups.

A post-hoc analysis was completed using the Tukey test. The time required to complete the linear osteotomies was compared using the Kruskal Wallis test for multiple independent samples. The software StatPlus: mac, AnalystSoft Inc. -statistical analysis program for macOS. Version v7. See https://www. analystsoft.com/en/ was used for the statistical analysis.

\section{RESULTS}

For each tip $(A, B, C)$, the timing of cuts ranged from $30 \mathrm{sec}$. to $5 \mathrm{~min}(2.30 \pm 1.76 \mathrm{~min}$ ) (Fig. 4 and Table 2 ). The significant lowest time was observed for Tip C $(p=0.00008)$ compared to Tip A and B. The maximum temperatures reached for each tip were as follows: Tip A: $48.0^{\circ} \mathrm{C}$, Tip B: $43.6^{\circ} \mathrm{C}$, and Tip C: $44.0^{\circ} \mathrm{C}$.

Overall the temperature change using the different tips (A, B, C) was less than 10 degrees (Fig. 5). The standard deviations were higher for Tip A. Tip B and Tip $C$ showed comparable standard deviations (Table 3). Statistical comparisons showed a higher maximum temperature for Tip B compared to Tip C $(p=0.00452)$. There were no significant differences between Tip A and Tip B (Table 3).

\section{DISCUSSION}

This experimental study aimed to evaluate the temperature changes and time required to complete linear osteotomies with three different Air scaler inserts. The operators in this study were calibrated, and the experimental design was carefully controlled. The temperature change in this study was less than 10 degrees for all tips $(A, B, C)$ (Fig. 5). This is less than the critical threshold, which could induce unwanted effects in osseous structures (Table 1).

It is possible that the irregular, saw type surface of Tip A contributed to the increased temperature change. 


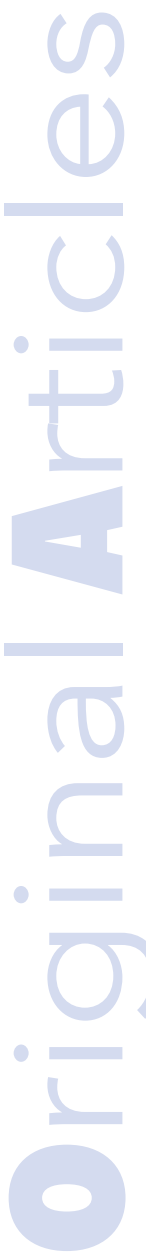

Tip B (ball shape) had a larger cutting surface area as compared to Tip A and Tip C, which was significantly thinner. Tip $B$ had an overall larger surface area as compared to Tip A and C. The diamond cut surface may lead to less heat generation. Tip C (chisel) had a smooth polished surface, which may account for less heat generation. This tip was not sharp and therefore additional mechanical pressure was required in order to create the osteotomy. A previous article [11] has demonstrated that an increase in temperature was inversely proportional to the diameter of the cutting tips.

There are very few studies which examine air scaler heat generation. There are no studies that exist which compare the air scaler to piezoelectic. There are studies which have compared piezoelectric to conventional drilling [12], and ultrasonic to conventional drilling [13].

These comparisons are important for any clinician who is considering adding one of these devices to their clinical practice.

The air scaler has multiple applications in dentistry. It has the capability to perform osteotomies, bone splitting, tooth removal, residual root removal, and window preparations for sinus augmentations [4]. In addition, it has been utilized to perform atraumatic extractions, wisdom tooth extractions, tori removal, endodontic post removal, calculus and caries removal. Because sonic instruments are driven by air compression, they easily connect to an existing dental unit. There is no additional purchase required for an external motor, or an external irrigation source [15]. This helps to minimize the cost incurred by the dentist. It is an appropriate instrument for those practitioners who are concerned with heat generated, while treating osseous tissues.

Other devices, such as piezosurgery have been utilized for dental osteotomy procedures. Piezosurgery has not only been applied in dentistry, but also in cranial and spinal surgery.

There are vast differences between piezosurgery and air scaler instruments. Piezosurgery conducts "piezoelectric vibrations". Piezosurgery operates at a much higher frequency (between 20,000 - 25,000 $\mathrm{Hz}$ ) than sonic instruments (average of $6,000 \mathrm{~Hz}$ ). It must be purchased as a separate device with a separate motor and irrigation source. For this reason, there is a significant cost difference between an air scaler and a piezosurgical unit.

Both air scalers and piezosurgery have been utilized in dentistry. Each instrument has the advantage of altering the osseous tissue, while sparing soft tissue structures. However, previous studies and evidence suggest that piezosurgery may generate a high amount of heat production $[9,15,16]$. Without doubt, it is up to the individual practitioner and the clinical indication which device is appropriate for their clinical practice.

Overall, the air scaler does not induce significant thermal changes in the bone and can be used in a safe manner. The thermal increase induced in the bone by three different air scaler inserts are within a safe range. The experiment conditions along with the continuous irrigation during the procedures potentially contributed to this finding.

Although it was not analyzed in this study, the depth of the cut made depends on the design of the insert tip. Flat tips are more feasible for deeper cuts, while round tips are more feasible for superficial cuts and osteotomies. The time required for the completion of the osteotomies was dependent on the insert design; flat designs were more efficient for the linear osteotomy completion.

This study's strengths are the strict calibration of the operators, and the experimental set-up that allowed the control of all the experimental variables. This study's limitations are that just three air scaler inserts were evaluated, and therefore the results cannot be extrapolated to other air scaler devices and inserts. Given that the air scaler works with the dental unit's air supply, and these vary among dental units, further evaluations are required with different air and power settings.

\section{CONCLUSION}

Osseous site preparation can be achieved with the air scaler; different air scaler inserts may be utilized without inducing significant thermal changes in the bone, as long as the conditions remain within the limits of the above experimental set-up.

\section{CONFLICT OF INTEREST}

None declared.

\section{AUTHOR CONTRIBUTIONS}

DM, GER: Concept. DM, GER, SL, KK: Protocol. DM, SL, GER, FJ: Data gathering and analysis. DM, RDG, KK, GER: Manuscript revision.

\section{ACKNOWLEDGMENTS}

None. 


\section{REFERENCES}

1. Strbac GD, Unger E, Donner R, et al. Thermal effects of a combined irrigation method during implant site drilling. A standardized in vitro study using a bovine rib model. Clin Oral Implants Res. 2014;25(6):665-674. doi: 10.1111/clr.12032. Full text link Pubmed Google Scholar Semantic Scholar Scopus WoS

2. AlAsseri N, Swennen G. Minimally invasive orthognathic surgery: a systematic review. Int J Oral Maxillofac Surg. 2018:47(10):1299-1310. doi: 10.1016/j.ijom.2018.04.017.

Full text link PubMed Google Scholar Scopus WoS

3. Rashad A, Sadr-Eshkevari P, Heiland M, et al. Intraosseous heat generation during sonic, ultrasonic and conventional osteotomy. J Craniomaxillofac Surg. 2015;43(7):1072-1077. doi: 10.1016/j. jcms.2015.05.018.

Full text link PubMed Google Scholar Scopus WoS

4. Stacchi C, Berton F, Turco G, et al. Micromorphometric analysis of bone blocks harvested with eight different ultrasonic and sonic devices for osseous surgery. J Craniomaxillofac Surg. 2016;44(9):1143-1151. doi: 10.1016/j.jcms.2016.04.024.

Full text link PubMed Google Scholar Scopus WoS

5. Eriksson AR, Albrektsson T. Temperature threshold levels for heat-induced bone tissue injury: a vital-microscopic study in the rabbit. J Prosthet Dent. 1983;50(1):101-107. doi: 10.1016/00223913(83)90174-9.

Full text link PubMed Google Scholar Scopus WoS

6. Eriksson AR, Albrektsson T. Assessment of bone viability after heat trauma. A histological, histochemical and vital microscopic study in the rabbit. Scand J Plast Reconstr Surg. 1984;18(3):261268. doi: 10.3109/02844318409052849.

PubMed Google Scholar Scopus WoS

7. Noble B. Bone microdamage and cell apoptosis. Eur Cell Mater. 2003;6:46-55; discusssion 55. doi: 10.22203/ecm.v006a05.

Full text link PubMed Google Scholar Scopus

8. Eriksson AR, Albrektsson T. The effect of heat on bone regeneration: an experimental study in the rabbit using the bone growth chamber. J Oral Maxillofacial Surg. 1984;42(11):705-711. doi: 10.1016/0278-2391(84)90417-8.

Full text link PubMed Google Scholar Scopus WoS
9. Rashad A, Kaiser A, Prochnow N, et al. Heat production during different ultrasonic and conventional osteotomy preparations for dental implants. Clin Oral Implants Res. 2011;12(22):1361-1365. doi: 10.1111/j.1600-0501.2010.02126.x.

Full text link PubMed Google Scholar Scopus WoS

10. Strbac GD, Giannis K, Unger E, et al. A novel standardized bone model for thermal evaluation of bone osteotomies with various irrigation methods. Clin Oral Implants Res. 2014;25(5):622631. doi: $10.1111 / \mathrm{clr}$.12090.

PubMed Google Scholar Scopus WoS

11. Stelzle F, Frenkel C, Reimann M, et al. The effect of load on heat production, thermal effects and expenditure of time during implant site preparation - an experimental ex vivo comparison between piezosurgery and conventional drilling. Clin Oral Implants Res. 2014;25(2):e140-e148. doi: 10.1111/clr.12077. Full text link PubMed Google Scholar Scopus WoS

12. Rashad A, Sadr-Eshkevari P, Heiland M, et al. Practitioner experience with sonic osteotomy compared to bur and ultrasonic saw: a pilot in vitro study. Int J Oral Maxillofac Surg. 2015;44(2):203-208. doi: 10.1016/j.ijom.2014.09.004.

Full text link PubMed Google Scholar Scopus WoS

13. Szalma J, Kiss C, Gurdán Z, et al. Intraosseous heat production and preparation efficiency of surgical tungsten carbide round drills: the effect of coronectomy on drill wear. J Oral Maxillofac Surg. 2016;74(3):442-452. doi: 10.1016/j.joms.2015.11.012. Full text link PubMed Google Scholar Scopus WoS

14. Heinemann F, Hasan I, Kunert-Keil C, et al. Experimental and histological investigations of the bone using two different oscillating osteotomy techniques compared with conventional rotary osteotomy. Ann Anat. 2012;194(2):165-170. doi: 10.1016/j. aanat.2011.10.005

PubMed Google Scholar Scopus WoS

15. Möhlhenrich SC, Modabber A, Steiner T, et al. Heat generation and drill wear during dental implant site preparation: systematic review. Br J Oral Maxillofac Surg. 2015;53(8):679-689. doi: 10.1016/j.bjoms.2015.05.004.

Full text link PubMed Google Scholar Scopus WoS
Dana M. MARZOCCO

DMD, Clinical Assistant Professor Department of Prosthodontics and Digital Technology Stony Brook, New York, USA

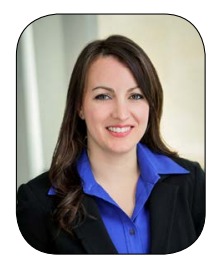

Dr. Dana M. Marzocco works in private practice in New Hyde Park, New York. Her practice is limited to Prosthodontics. She holds a faculty position as a Clinical Assistant Professor at the Stony Brook University, School of Dental Medicine, located in Stony Brook, New York. In addition, Dr. Marzocco lectures on various implant and restorative topics. 


\section{Questions}

1.The Air scaler device operates using compressed air at a frequency of:
Da. $2000 \mathrm{~Hz}$;
Db. $4000 \mathrm{~Hz}$;
]c. $6000 \mathrm{~Hz}$;
d. $8000 \mathrm{~Hz}$.

2. If temperature $\left({ }^{\circ} \mathrm{C}\right)$ were to increase during a procedure, the operator would be concerned. How many degrees of an increase would be a concern?

Da. 8 degrees;

ab. 10 degrees;

ac. 12 degrees;

口d. 15 degrees;

3. An Air scaler device can be utilized in which of the following procedures?
Da. Sinus augmentation;
ab. Harvesting bone;
uc. Osteotomies;
ad. All of the above.

4. Previous studies have shown that heating osseous tissue over $50^{\circ} \mathrm{C}$ for a duration of time has induced in vitro necrosis. After what amount of time does the necrosis occur?
Da. 30 seconds;
ab. 45 seconds;
ac. 1 minute;
ad. 2 minutes. 